\title{
A Study on Customer's Preference for Personal Vehicle Insurance Provided by Different Insurance Companies in Bengaluru
}

\author{
Swati Basu Ghose ${ }^{1}$ \& Anima Akanchha ${ }^{2}$ \\ ${ }^{1}$ Assistant Professor, ${ }^{2}$ PGDM Scholar \\ Ramaiah Institute of Management, Bengaluru 560054, Karnataka, India \\ Email: swatibg@msrim.org
}

Area/Section: Business Management.

Type of the Paper: Empirical Research.

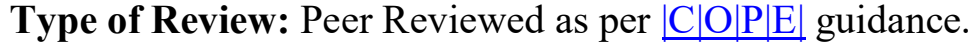

Indexed in: OpenAIRE.

DOI: http://doi.org/10.5281/zenodo.3997396.

Google Scholar Citation: IJMTS.

\section{How to Cite this Paper:}

Ghose, Swati Basu., \& Akanchha, Anima. (2020). A Study on Customer's Preference for Personal Vehicle Insurance Provided by Different Insurance Companies in Bengaluru. International Journal of Management, Technology, and Social Sciences (IJMTS), 5(2), 69-79.

DOI: http://doi.org/10.5281/zenodo.3997396.

International Journal of Management, Technology, and Social Sciences (IJMTS)

A Refereed International Journal of Srinivas University, India.

(C) With Authors.

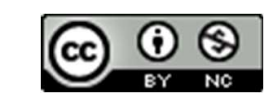

This work is licensed under a Creative Commons Attribution-Non-Commercial 4.0 International License subject to proper citation to the publication source of the work.

Disclaimer: The scholarly papers as reviewed and published by the Srinivas Publications (S.P.), India are the views and opinions of their respective authors and are not the views or opinions of the SP. The SP disclaims of any harm or loss caused due to the published content to any party. 


\title{
A Study on Customer's Preference for Personal Vehicle Insurance Provided by Different Insurance Companies in Bengaluru
}

\author{
Swati Basu Ghose ${ }^{1}$ \& Anima Akanchha ${ }^{2}$ \\ ${ }^{1}$ Assistant Professor, ${ }^{2}$ PGDM Scholar \\ Ramaiah Institute of Management, Bengaluru 560054, Karnataka, India \\ Email: swatibg@msrim.org
}

\begin{abstract}
The primary purpose of vehicle insurance is to cover the vehicle against damage, personal injury, and third-party liability. In addition to this, some insurance companies also provide value-added services such as roadside assistance and other services in return of the amount called as premium which attracts a large number of customers. However, our study shows that vehicle owners give maximum importance to the cost of insurance in terms of the annual premium. Primary data has been collected through questionnaire and analysed to ascertain about the factors responsible for taking out vehicle insurance, choice between private and public sector insurance companies, preferred insurance companies among the major players in the field, factors that play a role in the customers' choice of a particular insurance company, customers' opinion about the affordability of the premium to be paid, customers' satisfaction with their chosen company, whether customers consider fast and efficient service as a deciding factor, and whether the brand value of the company plays a role in the customers' choice.
\end{abstract}

Keywords: Vehicle Insurance, Customer satisfaction, Insurance premium, Service quality.

\section{INTRODUCTION :}

Insurance is a means of protection from financial loss. The insurance sector is one of the most important sectors for the economic growth of the country. It facilitates economic transactions by transferring the risk to the third party. A large proportion of contribution in the insurance sector comes from vehicle insurance. This study focuses on the importance of vehicle insurance and helps us to understand the important factors which are considered by the customers before choosing their specific insurance company for personal vehicles, in the city of Bengaluru in India.

The insurance sector is one of the most important sectors for the economic growth of the country. Its importance was also mentioned and acknowledged at the United Nations Conference on Trade and Development (UNCTAD)which is the focal point of the United Nations for all matters related to insurance and development. The importance of insurance can be recognized by the fact that the insurance programme has been an integral part of UNCTAD's mandate since the establishment of the organization in 1964 [1]. As humans and their possessions are always prone to risk because of uncertainties, these uncertainties cause financial loss to them. Insurance offers protection from financial loss. It is a subpart of risk management used to hedge against risk.

In this paper, we collect and analyze the opinions of the customers, who avail the services of vehicle insurance companies in the North Bengaluru area, via a questionnaire which ascertains the customers' opinion about the factors responsible for taking out vehicle insurance, choice between private and public sector insurance companies, preferred insurance companies among the major players in the field, factors that play a role in the 
customers' choice of a particular insurance company, customers' opinion about the affordability of the premium to be paid, customers' satisfaction with their chosen company, whether customers consider fast and efficient service as a deciding factor, and whether brand value of the company plays a role in the customers' choice.

\section{LITERATURE REVIEW :}

Nowadays, many people prefer to have insurance to overcome the future uncertainties and some of which have been made compulsory under the law There are different types of insurances such as life insurance, health insurance, vehicle insurance, and others. Post liberalization, vehicle insurance has become very important from both social and economic point of view and this have been researched by various researchers across various countries. Kelly et al. [2] have focused on how regulation influences availability and profitability of auto insurance in the context of Canadian vehicle insurance. It was concluded that premium rate reduction orders, product reforms and the prices impact the premium. This research also studied impact of regulatory acts on the auto insurance sector. Dhar [3] has studied the performance of the insurance sector in India and found that the health sector and automobile insurance sectors are the key players of general insurance. Research conducted by Dutta and Mitra [4] has analyzed the factors affecting vehicle insurance in India. Sabiyam [5] has found that customers in Ghana who are likely to get the compensation amount eventually get fed-up of the delays in the process and leave it in the middle. The insurance companies try to get the maximum premium from the customers and give them a lower amount at the time of claims. Siddique et al. [6] have evaluated the disclosure policies in the financial statements of the insurance companies in Bangladesh. It showed a positive relationship between the disclosure and profitability and performance of the insurance sector. Gessese [7] conducted a study to examine the effect of motor insurance claims management process on customer satisfaction at Ethiopian Insurance Company. The research identified several elements of the motor insurance claim management process. LeVan and Le Thi [8] and Kor-Udom [9] analyze factors that affect the purchase of voluntary insurance by customers andby insurance brokers' preference of insurance companies. The paper by Meeboonsalang and Chaveesuk [10] presents an integrated model of customer loyalty in automobile insurance in Thailand. In Kahanen et al. [11], data mining technology is applied to determine insurance rates. Fraud in automobile insurance claims is becoming a matter of great concern for insurance companies all over the world. The studies on this aspect by Subudhi and Panigrahi $[12,13]$ provide different ways of detecting frauds in the Indian context. There is a body of literature that focusses on improving insurance rates via different approaches [14, 15]. Devlin [16] examines different automobile insurance regimes in the Canadian context. A similar study was done by Grace et al. [17] for the US automobile insurance market and by Peng at al. [18] for Taiwan. Discounts in automobile insurance is a lucrative way of attracting customers and the paper by Chan et al. [19] addresses the issues involved in deciding upon discounts offered to customers. Green fuel initiatives are becoming important in the automobile sector and the paper by Huang and Wang [20] examines the effect of such vehicles on the insurance market in Taiwan. The exact premium to be charged to customers is an important issue and the paper by Robinette and Wachtel [21] presents a case study on the effect on the overall revenue from the automobile insurance when the value of the insured amount is raised.

Insurance companies pay attention to have a good relationship with the customer and provide them a certain level of quality of service. The present paper focuses on the importance of vehicle insurance and customer preference for vehicle insurance between the public sector and private sector companies. Customers have a wide range of insurance companies to choose from. It can be either public sector or private sector. The customer has to choose between them which they do so by keeping in mind the premium paid by them, services received by them, and the satisfaction worth in terms of premium paid by them.

\section{RESEARCH DESIGN :}

\subsection{Statement of the Problem}

Vehicle insurance is mandatory for the customers and it has been also made compulsory by the law. Every owner must have the vehicle insurance be it two-wheeler or four-wheeler. Thus, there arises the need for a 
third party and its liability towards the damage of vehicle under the law. Therefore, vehicle insurance is important for the owners as it minimizes their risks and transfers the risk to the third party. Vehicle insurance can be done through various insurance companies, the private sector, public sector insurance companies, or banks. The customers have a wide variety of options to choose from. There is a competition among the companies and the customers have to choose between them. The choice of selection is based on the prices decided by the companies and customer satisfaction. The insurance companies claim to render a high quality of services to the customers. However, the actual scenario is different. There is a gap between the public sector insurance companies and private sector insurance companies with respect to the insurance premium charged by them, which affects the services provided by them, thus affecting customer satisfaction.

\subsection{Objectives}

The objectives of the study are as follows:

1. To study about insurance companies providing vehicle insurance in Bengaluru.

2. To identify the factors considered by customers for opting for a vehicle insurance.

3. To understand important factors that affect customers preference in selecting an insurance company.

\subsection{Hypothesis}

Null hypothesis: There is no significant relationship between the customer preference for an insurance company and the premiums paid.

Alternative hypothesis: There is a significant relationship between the customer preference for an insurance company and the premiums paid.

\subsection{Scope and Limitations of the Study}

The present study focuses on vehicle insurance by the vehicle owners and is conducted in North Bengaluru. It includes the various insurance companies preferred by customers. The limitations of the study are the following:

1. The study is only conducted in North Bengaluru.

2. Primary data collection method has been used in the form of questionnaire and the study has been conducted within a short span of time.

3. The study is only restricted to vehicle insurance.

\subsection{Methodology and Data Collection}

Type of Study: Descriptive Research

Sampling Plan: (a) Sampling Unit: Customers who own a vehicle and have a vehicle insurance from their respective companies. (b) Sampling Techniques: Convenience (Non-probability) sampling methods are used. (c) Sample Size: 100.

Primary Research Data: The primary data was collected from selected customers who own a vehicle and have taken a vehicle insurance using Simple Random sampling techniques, with the help of questionnaires. The questionnaire was based on Likert five-point scale. Total questionnaires were circulated to customers, out of which responses were received. The present study is mainly based on the survey conducted and questionnaires are based on Likert and semantic scales.

Secondary Research Data: The secondary data is collected from various sources like existing research papers, journals, and databases. It covers the conceptual part of the study and the main source of the secondary data is the official website of the insurance companies, research papers, article, etc.

\section{DATA ANALYSIS :}

In the following, we present the data collected in both tabular and graphical form and make inferences from them.

\subsection{Factors Considered by Customers}

Fig. 1 presents the factors considered by customers in deciding the reason for opting for insurance. Interpretation: It can be observed that $29 \%$ respondents opt for vehicle insurance as it pays for damages, $21 \%$ as they think it reduces the potential liability for them, $17 \%$ of respondents think it shares the risk between them and the insurer, $8 \%$ of respondents have done their vehicle insurance for value added services, $25 \%$ 
respondents have opted for the vehicle insurance as it is made compulsory by the government.

Inference: It can be concluded that majority of respondents go for vehicle insurance as it pays for the damages which can occur in the future.

\begin{tabular}{|l|l|}
\hline Factors & Percentage \\
\hline Pays for damage & $29 \%$ \\
\hline Reduces liability & $21 \%$ \\
\hline Risk sharing & $17 \%$ \\
\hline Value added services & $8 \%$ \\
\hline $\begin{array}{c}\text { Compulsory by the } \\
\text { government }\end{array}$ & $25 \%$ \\
\hline Total & $100 \%$ \\
\hline
\end{tabular}

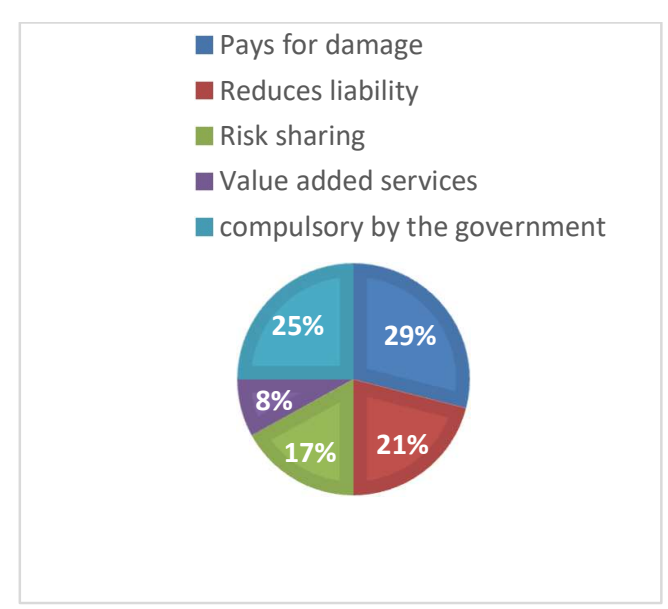

Fig. 1: Factors considered by customers

\subsection{Preferred Sector by Customers}

Fig. 2 present the customers' preference for public or private sector.

Interpretation: From the data, $63 \%$ respondents prefer to go for private sector and $37 \%$ respondents prefer public sector.

Inference: From the data, it can be inferred that majority of the respondents prefer private sector for vehicle insurance.

\begin{tabular}{|l|l|}
\hline Sector & Percentage \\
\hline Public sector & $37 \%$ \\
\hline Private sector & $63 \%$ \\
\hline Total & $100 \%$ \\
\hline
\end{tabular}

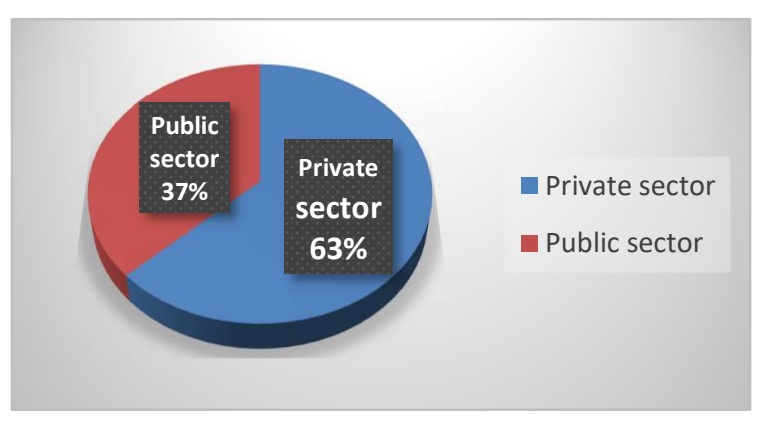

Fig. 2: Preferred sector by customers

\subsection{Companies Preferred by Customers}

Fig. 3 gives the data about the companies preferred by customers. In the Table 3, many customers ticked more than one company, since they switch companies year to year, and hence the total number is more than 100 which was the sample size.

Interpretation: From the data, it is observed that 34 respondents prefer ICICI Lombard, 25 respondents prefer HDFC ERGO, 20 respondents prefer TATA AIG, 23 respondents prefer The New India Assurance company, 16 respondents prefer The Oriental Insurance Company, 20 respondents prefer Bajaj Alliance and 32 respondents prefer the other companies for their vehicles.

Inference: From the data, it is analysed that majority of respondents prefer ICICI Lombard for their vehicle 
International Journal of Management, Technology, and Social Sciences (IJMTS), ISSN: 2581-6012, Vol. 5, No. 2, August 2020.

insurance and HDFC ERGO.

\begin{tabular}{|l|l|l|}
\hline Companies & Frequency & Percentage \\
\hline $\begin{array}{l}\text { ICICI Lombard } \\
\text { GIC. Ltd }\end{array}$ & 34 & $20 \%$ \\
\hline $\begin{array}{l}\text { HDFC ERGO } \\
\text { General } \\
\text { Insurance } \\
\text { Company }\end{array}$ & 25 & $15 \%$ \\
\hline TATA AIG & 20 & $12 \%$ \\
\hline $\begin{array}{l}\text { The New India } \\
\text { Assurance } \\
\text { Company } \\
\text { Limited }\end{array}$ & 23 & $13 \%$ \\
\hline $\begin{array}{l}\text { The Oriental } \\
\text { Insurance Co. }\end{array}$ & 16 & $9 \%$ \\
\hline $\begin{array}{l}\text { Bajaj Alliance } \\
\text { GIC Ltd. }\end{array}$ & 20 & $12 \%$ \\
\hline Others & 32 & $19 \%$ \\
\hline Total & 170 & $100 \%$ \\
\hline
\end{tabular}

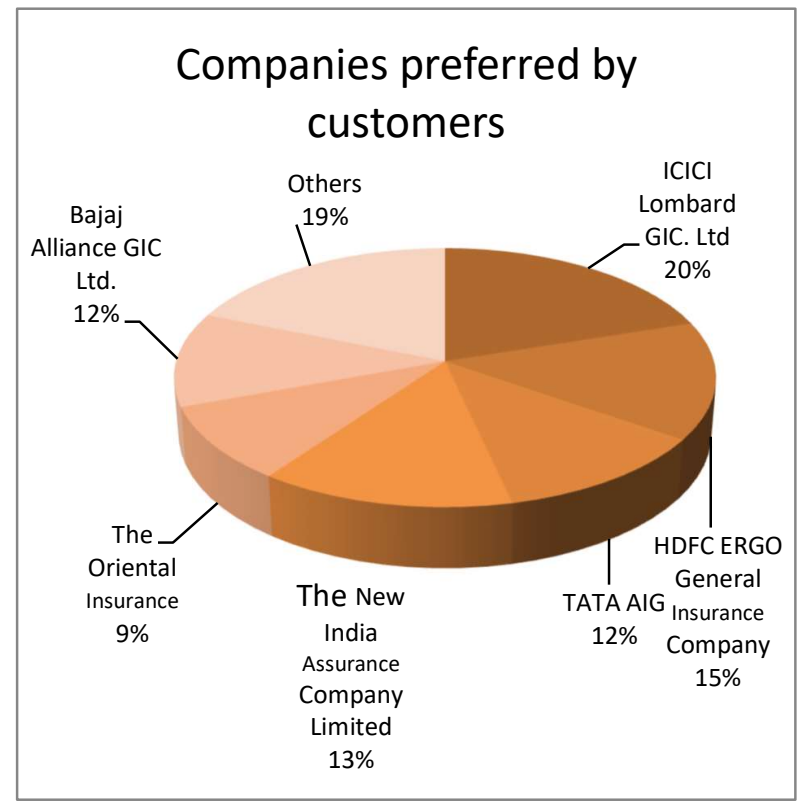

Fig. 3: Companies preferred by customers

\subsection{Factors Considered by Customers for Choosing the Insurance Company}

Fig. 4 gives the data about the reason that a customer prefers his/her chosen company.

Interpretation: It can be seen that $22 \%$ of respondents choose their preferred insurance because of easy access, $23 \%$ respondents choose because of prompt service, $30 \%$ respondents because of insurance coverage, and $25 \%$ respondents choose the respective insurance company because of the affordability of the premium rates. Inference: It can be inferred that majority of the respondents go with their respective chosen companies because of the insurance coverage given by them as per their policy.

\begin{tabular}{|l|l|}
\hline Factors & Percentage \\
\hline Easy Access & $22 \%$ \\
\hline Prompt service & $23 \%$ \\
\hline Insurance coverage & $30 \%$ \\
\hline Affordable premium & $25 \%$ \\
\hline
\end{tabular}

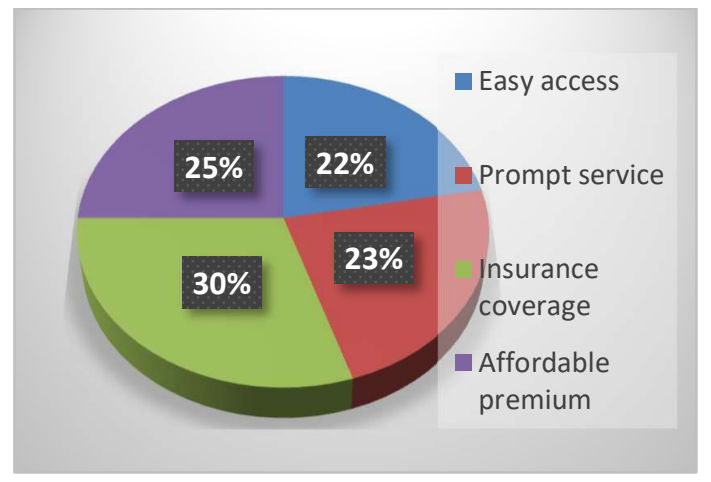

Fig. 4: Factors considered by customers for choosing the insurance company

\subsection{Feeling of Customers about the Amount of Premium}

Fig. 5 presents the data pertaining to the customers' opinion on the amount of premium paid for the insurance. Interpretation: It can be concluded that $36 \%$ of the respondents are neutral with the premium rates paid by them, that is, they are neither expensive nor inexpensive, $26 \%$ respondents agree, $5 \%$ respondents strongly 
agree, $22 \%$ respondents disagree and $5 \%$ strongly disagree.

Inference: It can be concluded that majority of the respondents are neutral with the premium rates paid by them and they feel that it is neither expensive nor inexpensive with respect to the services availed by them. $26 \%$ respondents feel that the more premium they pay, the better services they will be offered.

\begin{tabular}{|l|l|}
\hline Opinion & Percentage \\
\hline Strongly disagree & $11 \%$ \\
\hline Disagree & $22 \%$ \\
\hline Neutral & $36 \%$ \\
\hline Agree & $26 \%$ \\
\hline Strongly agree & $5 \%$ \\
\hline Total & $100 \%$ \\
\hline
\end{tabular}

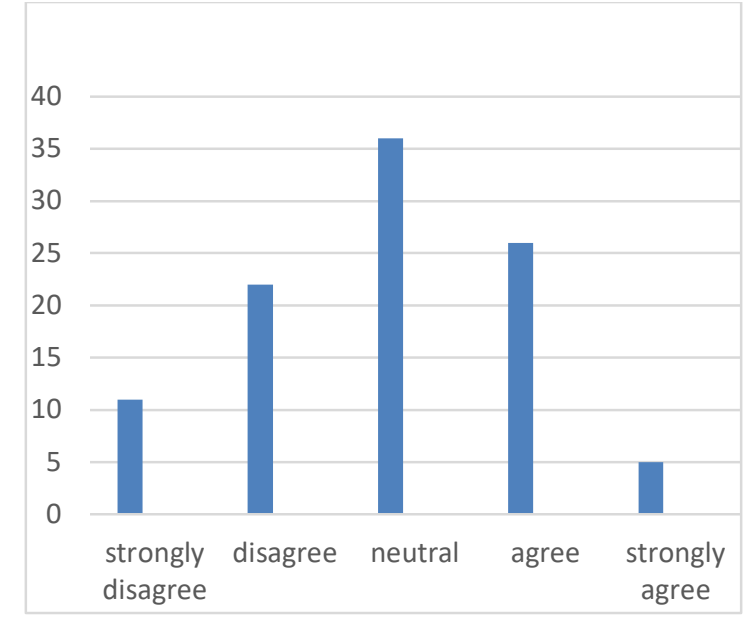

Fig 5: Customers feel that premium paid is expensive

\subsection{Customers' Satisfaction with the Existing Insurance Company}

Fig. 6 collates the data on how satisfied the customers are with their present insurance provider.

Interpretation: It can be observed that $38 \%$ respondents are satisfied with their existing insurance company, $16 \%$ respondents are highly satisfied, $28 \%$ respondents are neutral to it, $16 \%$ respondents are dissatisfied with their current insurance company and $2 \%$ respondents are highly dissatisfied.

Inference: It can be inferred that majority of the respondents are satisfied with their existing insurance company.

\begin{tabular}{|l|l|}
\hline Opinion & Percentage \\
\hline Highly satisfied & $13 \%$ \\
\hline Satisfied & $38 \%$ \\
\hline Neutral & $28 \%$ \\
\hline Unsatisfied & $16 \%$ \\
\hline Highly Unsatisfied & $2 \%$ \\
\hline Total & $100 \%$ \\
\hline
\end{tabular}




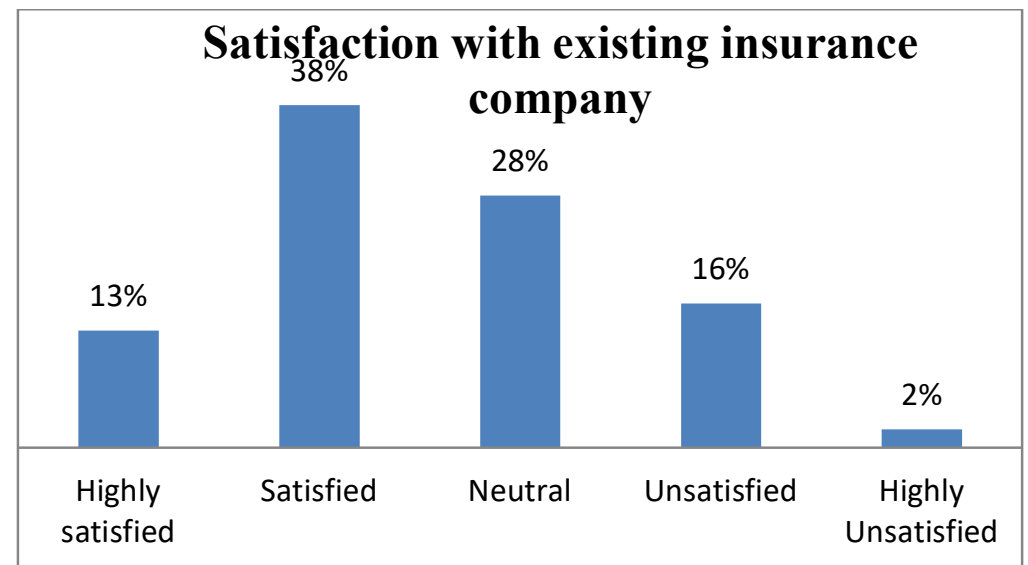

Fig. 6: Satisfaction with the existing insurance company

\subsection{Customers' Opinion on Fast and Efficient Service}

Fig. 7 gives the data on how the customers feel about the service of their insurance company being fast and efficient.

Interpretation:It can be seen that 45 respondents agree that their insurance company provided fast and efficient services, 27 respondents strongly agree, 17 respondents are neutral, 8 disagree and 3 strongly disagree with the efficiency and the speed of their insurance of the company.

Inference: It can be inferred that that majority of the respondents consider their choosen insurance company fast and efficient and are satisfied.

\begin{tabular}{|l|l|}
\hline Opinions & Percentage \\
\hline Strongly disagree & $3 \%$ \\
\hline Disagree & $8 \%$ \\
\hline Neutral & $17 \%$ \\
\hline Agree & $45 \%$ \\
\hline Strongly agree & $27 \%$ \\
\hline Total & $100 \%$ \\
\hline
\end{tabular}

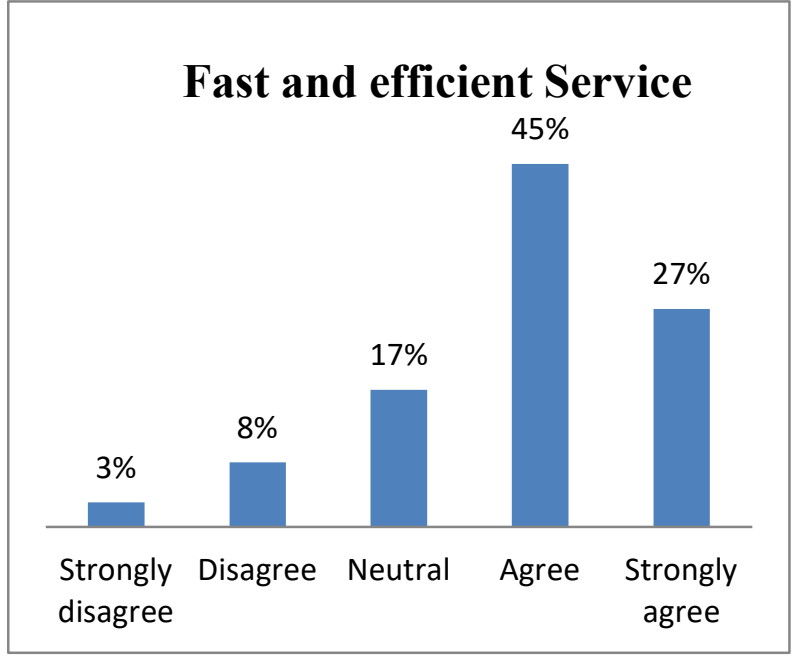

Fig. 7: Fast and efficient services considered before choosing the insurance company

\subsection{Effect of Brand on Customers' Choice}

Fig. 8 presents data on the effect of the brand of the insurance company on the choice of customers.

Interpretation: From the above chart, it can be observed that 58 respondents have a strong affinity towards the brand of their insurance company, 28 respondents agree, 10 respondents are neutral to it, 3 respondents disagree and 1 respondent strongly disagree.

Inference: From the above chart, it can be analysed that majority of the respondents prefer their vehicle to be insured by the branded and reputed companies. For them, the brand of the company matters. 


\begin{tabular}{|l|l|}
\hline Opinions & Percentage \\
\hline Strongly disagree & $1 \%$ \\
\hline Disagree & $3 \%$ \\
\hline Neutral & $10 \%$ \\
\hline Agree & $28 \%$ \\
\hline Strongly agree & $58 \%$ \\
\hline Total & $100 \%$ \\
\hline
\end{tabular}

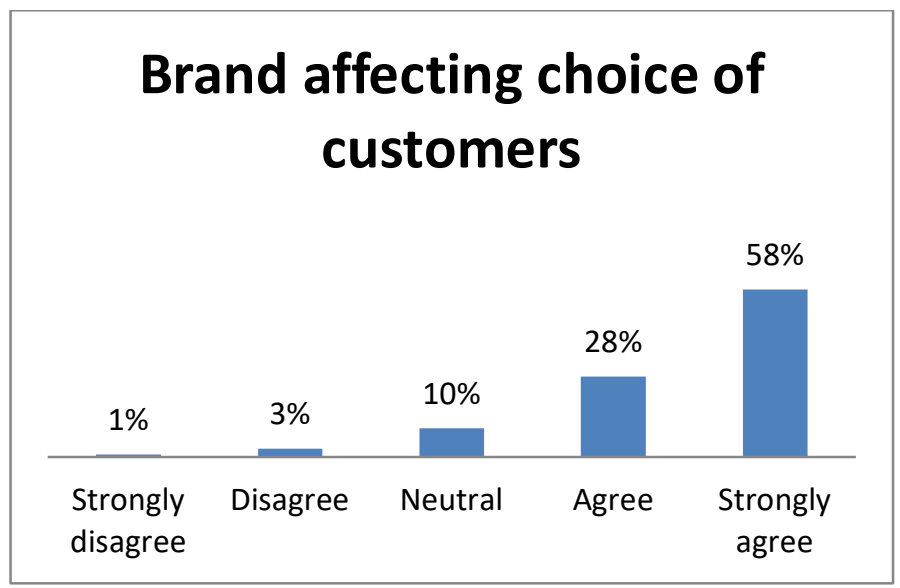

Fig. 8: Brand affecting choice of the customers

\subsection{Hypothesis Testing on Importance of Premium Amount}

It is widely believed that Indian customers give a great deal of importance to the amount of money paid as premium. In the following, we carry out a hypothesis testing to analyze the relationship between customers' preference for a company and the premium paid.

Null hypothesis: There is no significant relationship between the customer preference for an insurance company and the premiums paid.

Alternative hypothesis: There is significant relationship between the customer preference for an insurance company and the premiums paid.

Table 1: Result of Hypothesis Testing via Chi-Square Test

\begin{tabular}{|l|l|l|l|}
\hline & Value & df & Asymptotic Significance(2-sided) \\
\hline Pearson Ch-Square & $35.738^{\text {a }}$ & 20 & 0.017 \\
\hline Likelihood Ratio & 40.670 & 20 & 0.004 \\
\hline Linear-by-Linear Association & 0.023 & 1 & 0.880 \\
\hline Number of Valid Cases & 100 & & \\
\hline a22 cells (73.3\%) have expected count less than 5. The minimum expected count is 0.06 \\
\hline
\end{tabular}

Interpretation: From Table 1, we can observe that chi-square (0.017) which signifies that there is a significant relation between the customer preference for an insurance company and the premiums paid. Here, the significance value is 0.017 which is less than 0.05 , therefore we reject the null hypothesis and accept the alternative hypothesis, i.e., there is a significant relation between the customer preference for an insurance company and the premiums paid.

Inference: It is clearly observed that premium paid by the customer affects the choice of the companies chosen by them. Premium played a very vital in selecting an insurance company. The amount of premium also affects the extra value-added services which varies from company to company and their policies.

\section{FINDINGS :}

The following are the broad findings of this study. 
1. Majority of respondents go for vehicle insurance as it pays for the damages which can occurred in the future.

2. Majority of the respondents prefer private sector for vehicle insurance because of the services provided by them.

3. Majority of respondents prefer ICICI Lombard for their vehicle insurance.

4. Majority of the of the respondents go with their respective chosen companies because of the insurance coverage given by them as per their policy.

5. Majority of the respondents are neutral with the premium rates paid by them and they feel that it is neither expensive nor inexpensive with respect to the services availed by them.

6. Majority of the respondents have bought the insurance policy from the insurance company.

7. Majority of the respondents have chosen their insurance company because of the fast and efficient services provided by them.

8. Majority of the respondents feel that the premiums paid by them are worth the service availed which includes prompt service and value-added services.

9. Majority of the respondents prefer their vehicle to be insured by the branded and reputed companies. For them, the brand of the company matters.

10. Majority of the respondents feel that the coverage amount received if any damage occurs is worth the premium paid by them.

11. Majority of the respondents get no claim bonus from their insurance company.

12. Majority of the respondents do not get the roadside assistance by their insurance companies in case of their accidental breakdown on the way. This depends on the policy taken by them.

13. It is clearly observed that most of the people are likely to refer their insurance company to their family and friends.

14. It is also found that there is a significant relationship between the customer preference for an insurance company and the premiums paid which mean the amount of premium affects the choice of the insurance company.

\section{CONCLUSIONS AND SUGGESTIONS :}

The vehicle insurance companies have a potential market with high returns which depends on the relationship between the service providers and the customers. The study reported in this paper will help in analyzing the customer behavior patterns and thus effective services and strategies can be formulated by the insurance company to promote their business. The digital era has made it possible for companies to devise new tools and services which are available on a $24 / 7$ basis, this attracting more potential customers and improve customer experience and satisfaction level.

The following suggestions, made based on the above study, can help insurance company to better market their products and services.

1. Insurance companies can extend customer support through mobile apps with more user friendly and updated features.

2. Insurance companies can provide more services at a discounted rate to loyal customers to retain them and can offer them referral points whenever they refer it to their family and friends.

3. Public sector insurance companies should try to provide more efficient services.

4. Private insurance companies can cut down the premium rates up to some extent or can provide more services with that premium amount.

5. They can also provide additional benefits to multi-vehicle families engaging with the same insurance provider.

6. Insurance companies can offer roadside assistance to the customers with minimal rate so they take can use this service too in case of any emergency while they are travelling at an unfamiliar place.

7. The insurance companies should do the verification process in case of damage by less consumption of time so that the customer can get the compensation amount on time. 
8. They should also take feedback from the customers time to time to know how satisfied they are with their current services offered and how can they improve.

\section{REFERENCES :}

[1] UNCTAD: About the Insurance Programme, https://unctad.org/en/Pages/DIAE/Enterprise\%20Development/Insurance/Insurance-about-the-

Programme.aspx (downloaded: 26 July, 2020).

[2] Kelly, M., Kleffner, A. E., \& Li, S. (2013). The Impact of Regulation on the Availability and Profitability of Auto Insurance in Canada. Assurances et Gestion des Risques, 81. Available at SSRN 1698042.

[3] Dhar, S. (2013). Performance of Indian Insurance Sector-A Critical Analysis. Prism India, OctoberDecember, 1-8.

[4] Dutta, M. M., \& Mitra, G. (2015). Factors affecting auto insurance in India. Indian Journal of Management Science, 5(2), $72-77$.

[5] Sabiyam, M. (2005). The Impact of Insurance on Transport Business in Ghana: A Case Study in Sunyani Municipality. A Master's Thesis submitted to Sunyani Polytechnic.

[6] Siddique, M. A. B., Neogy, T. K., \& Islam, M. R. (2014). Variations in opinions toward disclosure trend of insurance companies in Bangladesh: an empirical study. American Journal of Trade and Policy, 1(1), 4250.

[7] Gessese, Y.B. (2018). The Effect of Motor Insurance Claim Management on Customer Satisfaction at Ethiopian Insurance Corporation, MBA Thesis, Department of Business Administration, School of Graduate Studies, St. Mary's University, Addis Ababa, Ethiopia.

[8] LeVan, H. U. Y., \& Le Thi, H. G. (2010). Factors Affecting the Purchase of Voluntary Automobile Insurance. Journal of Economic Development, 194, 13-20.

[9] Kor-Udom, M. (2016). Using Heuristic Cues for Insurance Broker'S Intention to Select Automobile Insurance Companies. The Journal of Risk Management and Insurance, 20(1), 67-102.

[10] Meeboonsalang, W., \& Chaveesuk, S. (2019). An Integrated Model of Customer Loyalty in Automobile Insurance in Thailand. Asia-Pacific Social Science Review, 19(3), 203-216.

[11] Kahane, Y., Levin, N., Meiri, R., \& Zahavi, J. (2007). Applying data mining technology for insurance rate making: an example of automobile insurance. Asia-Pacific Journal of Risk and Insurance, 2(1), 1-19.

[12] Subudhi, S., \& Panigrahi, S. (2020). Two-Stage Automobile Insurance Fraud Detection by Using Optimized Fuzzy C-Means Clustering and Supervised Learning. International Journal of Information Security and Privacy (IJISP), 14(3), 18-37.

[13] Subudhi, S., \& Panigrahi, S. (2018). Detection of Automobile Insurance Fraud Using Feature Selection and Data Mining Techniques. International Journal of Rough Sets and Data Analysis (IJRSDA), 5(3), 1-20.

[14] Guillen, M., Nielsen, J. P., Ayuso, M., \& Pérez-Marín, A. M. (2019). The use of telematics devices to improve automobile insurance rates. Risk analysis, 39(3), 662-672.

[15] Blesa, A., Íñiguez, D., Moreno, R., \& Ruiz, G. (2020). Use of open data to improve automobile insurance premium rating. International Journal of Market Research, 62(1), 58-78.

[16] Devlin, R. (2019). A Comparison of Automobile Insurance Regimes in Canada. Assurances et gestion des risques/Insurance and Risk Management, 86(1-2), 55-96.

[17] Grace, M., Leverty, J. T., \& Powell, L. (2019). Cost Trends and Affordability of Automobile Insurance in the US. Journal of Insurance Regulation, 38(7), 1-24. 
[18] Peng, S. C., Li, C. S., \& Liu, C. C. (2016). Deregulation, pricing strategies, and claim behavior in the Taiwan automobile insurance market. Emerging Markets Finance and Trade, 52(4), 869-885.

[19] Chan, L. F., Huang, Y. C., \& Tzeng, L. Y. (2016). Who Obtains Greater Discounts on Automobile Insurance Premiums?. The Geneva Risk and Insurance Review, 41(1), 48-72.

[20] Huang, J. S., \& Wang, K. C. (2019). Are Green Car Drivers Friendly Drivers? A Study of Taiwan's Automobile Insurance Market. Journal of Risk and Insurance, 86(1), 103-119.

[21] Robinette, C. J., \& Wachtel, D. (2019). Raising compulsory automobile insurance minimum amounts: a case study from the United states. Insurance Review, (4), 59-71. 